\title{
Dynamic response of the vegetation carbon storage in the sanjiang plain to changes in land use/cover and climate
}

\author{
Haiyan Li, Yi Qu, Xingyu Zeng, Hongqiang Zhang, Ling Cui and Chunyu Luo* (0)
}

\begin{abstract}
Large-scale human activities especially the destruction of forest land, grassland, and unused land result in a large amount of carbon release into the atmosphere and cause drastic changes in land use/cover in the Sanjiang Plain. As a climate change-sensitive and ecologically vulnerable area, the Sanjiang Plain ecosystem's carbon cycle is affected by significant climate change. Therefore, it is important that studying the impact of the changes in land use/cover and climate on vegetation carbon storage in the Sanjiang Plain. Remote sensing, temperature, and precipitation data in four periods from 2001 to 2015 are used as bases in conducting an analysis of land use/cove types and spatio-temporal variation of vegetation carbon density and carbon storage in growing season using model and related analysis methods. Moreover, the impact of land use/cover change and climate change on vegetation carbon density and carbon storage is discussed. The findings are as follows. (1) Cultivated land in the Sanjiang Plain increased, while forest land, grassland and unused land generally decreased. (2) Vegetation carbon density increased, in which the average carbon density of cultivated land, grassland, and unused land varied insignificantly, while that of forest land increased continuously from $4.18 \mathrm{~kg} \mathrm{C} / \mathrm{m}^{2}$ in 2001 to $7.65 \mathrm{~kg} \mathrm{C} / \mathrm{m}^{2}$ in 2015. Vegetation carbon storage increased from $159.18 \mathrm{Tg}$ C in 2001 to $256.83 \mathrm{Tg}$ C in 2015, of which vegetation carbon storage of forest land contributed $94 \%$ and 97\%, respectively. (3) Conversion of land use/cover types resulted in a 22.76-TgC loss of vegetation carbon storage. Although the forest land area decreased by $3389.5 \mathrm{~km}^{2}$, vegetation carbon storage in the research area increased by $97.65 \mathrm{Tg} C$ owing to the increase of forest carbon density. (4) Pixel-by-pixel analysis showed that vegetation carbon storage in the majority of the areas of the Sanjiang Plain are negatively correlated with temperature and positively correlated with precipitation. The results showed that changes of land use/cover types and vegetation carbon density directly lead to a change in vegetation carbon storage, with the change of forest vegetation carbon density being the main driver affecting vegetation carbon storage variation. The increase of temperature mainly suppresses the vegetation carbon density, and the increase of precipitation mainly promotes it.
\end{abstract}

Keywords: Vegetation carbon storage, Land use/cover change, Climate change, Vegetation carbon density, The Sanjiang Plain

*Correspondence: iamluo2002@163.com

HIST-HB, National and Local Joint Laboratory of Wetland and Ecological Consernation, Institute of Natural Resources and Ecology, Heilongjiang Academy of Sciences, Harbin 150040, China

\section{Introduction}

The terrestrial ecosystem is one of the important carbon pools and an important link in the interaction between human activities and climate change [1]. Land use/cover change can directly affect the structure and function of land ecosystem. Therefore, carbon storage change in land ecosystem causes a change in carbon source and carbon sink, which is among the main human driving forces of 
carbon circulation in the current land biosphere. Global climate change causes a change in the vegetation growth environment, thereby affecting vegetation growth, structure, and function. Human activities and global climate change pose a double threat substantially affecting the carbon cycle of terrestrial ecosystems. Analyzing the impact of regional climate change and human activity on carbon cycles in terrestrial ecosystems provides important guidance for an accurate understanding of carbon cycle processes and the formulation of relevant policies.

Vegetation is the main body of the terrestrial ecosystem [2] and plays an extremely important role in the global carbon cycle. The scientific and timely evaluation of the response of the vegetation carbon storage to human activities and climate change is a hotspot in current climate change and regional sustainable development research [3-5]. In recent years, scholars have focused on the impact of land use/cover on the vegetation carbon storage. De Jong [6] believes that land use/cover has changed the ecosystem carbon density in Chiapas. Martens [7] has concluded that the carbon storage of the forest land in the U.S. is $29 \%$ and $46 \%$ higher than that of the local grassland and cultivated land, respectively. Erb [8] has quantitatively studied the impact of human activities in Australia on the carbon storage of surface vegetation. Erb [8] has concluded that the conversion of forest land into cultivated land, grassland, and urban land reduces the vegetation carbon storage by $77 \%$ and that the decrease in forest age and the change in tree species decrease the forest carbon storage by $30 \%$. The achievements of Hutyra[9] in studying the effect of the vegetation cover change on the carbon storage contribute to the evaluation and the analysis of urban carbon sequestration potential. Wu et al. [10] estimated the vegetation carbon storage in a mining area in Jining and concluded through analysis that coal mining activities damage the cultivated land and ecological environment in the mining area, leading to immense loss of carbon storage, but land reclamation effectively recovered part of the lost carbon. Kong et al. [11] used a typical desert oasis area as their research object and concluded that land use/cover vegetation change leads to an overall increase trend of carbon storage in Linze Oasis. Moreover, they concluded that a change in cultivated land is a main factor affecting change in carbon storage. Zhu et al. [12] estimated the vegetation carbon storage in Qi River Basin of Taihang Mountain from 2005 to 2015, and predicted the carbon storage and carbon density of the ecosystem under different land use/cover change scenarios in 2025. They concluded that carbon sequestration capacity would be improved under ecological protection scenario. Wei et al. [13] analyzed the characteristics of vegetative cover change and vegetation carbon storage in the Yili area from 2005 to 2015.
They concluded that a change in land vegetation generally reduces vegetation carbon storage, while changes in grassland and agricultural land are important factors affecting the carbon storage of vegetation. However, studies on the spatiotemporal changes of the vegetation carbon storage involving the combined effects of regional land use/cover change and climate change are few, and this field needs improvement and breakthroughs in the future.

The Sanjiang Plain is located in a medium- and highlatitude region and extremely sensitive to climate change. At the same time, the reclamation of the Sanjiang Plain in a large area since the middle and late twentieth century has resulted in drastic land use/cover changes. A large number of forest lands, unused lands, and grasslands have been reclaimed into cultivated land, thereby reducing the productivity of vegetation and the input of soil organic matter and leading to the release of large amounts of carbon elements into the atmosphere [14]. However, few studies have been conducted on the spacetime change of vegetation carbon storage in the Sanjiang Plain under the double influence of land use/cover change and climate change. On the bases of Landsat-TM/ OLI, MODIS normalized difference vegetation index (NDVI) and meteorological data in four periods from 2001 to 2015, this study estimates the vegetation carbon density and carbon storage in the Sanjiang Plain in 2001, 2005, 2010 and 2015 by using model on the geographic information system (GIS) platform, and analyzes the time-space variation of carbon density and carbon storage for vegetation in this area. Moreover, this study explores the influence of land use/cover change and climate change on vegetation carbon density and carbon storage. The results are of important guiding significance for conducting a study on regional carbon sequestration and formulating the relevant policies.

\section{Study area}

The Sanjiang Plain is located in the northeast of Heilongjiang Province and formed by the impact of Heilongjiang, Songhua, and Wusuli Rivers. Its geographical coordinates are $43^{\circ} 49^{\prime} 55^{\prime \prime}-48^{\circ} 27^{\prime} 40^{\prime \prime} \mathrm{N}$ and $129^{\circ} 11^{\prime} 20^{\prime \prime}$ $135^{\circ} 05^{\prime} 26^{\prime \prime} \mathrm{E}$. The Sanjiang Plain has a total area of about $108900 \mathrm{~km}^{2}$ and is the largest and most concentrated wetland in China. Moreover, the Sanjiang Plain is one of the most critical areas for wetland and biodiversity conservation in the world and an important food production and reserve base in China. This area has four distinct seasons with long freezing period, annual average temperature of $1.6{ }^{\circ} \mathrm{C}-3.9^{\circ} \mathrm{C}$, and annual precipitation of $500-700 \mathrm{~mm}$ that is concentrated in summer and autumn, and humid and semihumid continental 
monsoon climate. The distribution of the study area is shown in Fig. 1.

\section{Methods}

\section{Data sources and treatment}

TM/OLI, MODIS NDVI and meteorological data were the main data sources.The time span was 2001-2015 and divided into four periods: 2001, 2005, 2010, and 2015. The TM/OLI remote sensing image was obtained from the international scientific data service platform (http:// www.cnic.cas.cn/) with a resolution of $30 \mathrm{~m}$. The original remote sensing image was preprocessed by geometric correction, radiometric calibration, atmospheric correction, and clipping.The MODIS NDVI was a MOD13Q1 product that covered the Sanjiang Plain and provided free of charge on the official NASA website(http://www. nasa.gov/), and its spatial and temporal resolutions were $250 \mathrm{~m}$ and 16 days, respectively. The time range was the growing season of each period (April to October), a total of 104 images, and this study used the 16 days synthetic data of MOD13Q1NDVI products to generate monthly NDVI data through maximum value compositing (MVC). The meteorological data included the temperature and the precipitation data of 34 meteorological stations in and around the Sanjiang Plain from April to October and were provided by the Heilongjiang Meteorological Information Center (Fig. 1).

\section{Interpretation of land use/cover types}

According to the Macro Investigation and Dynamic Research of the Resource and Environment [15] and the current land use/cover characteristics in the study area, TM/OLI remote sensing images were interpreted by using the support vector machine (SVM) algorithm in the supervised classification method. The land use/cover in the study area was classified into six types, including forest land, cultivated land, grassland, construction land, water area, and unused land, and the spatial distribution maps of land use/cover types in the study area in 2001, 2005, 2010, and 2015 were obtained (Fig. 2), and the classification results were evaluated on the basis of the field verification points. The current study randomly sampled 180 points for field-test verification (Fig. 2).The classification accuracy of each type of supervised classification results in the Phase 4 sensing images and the overall

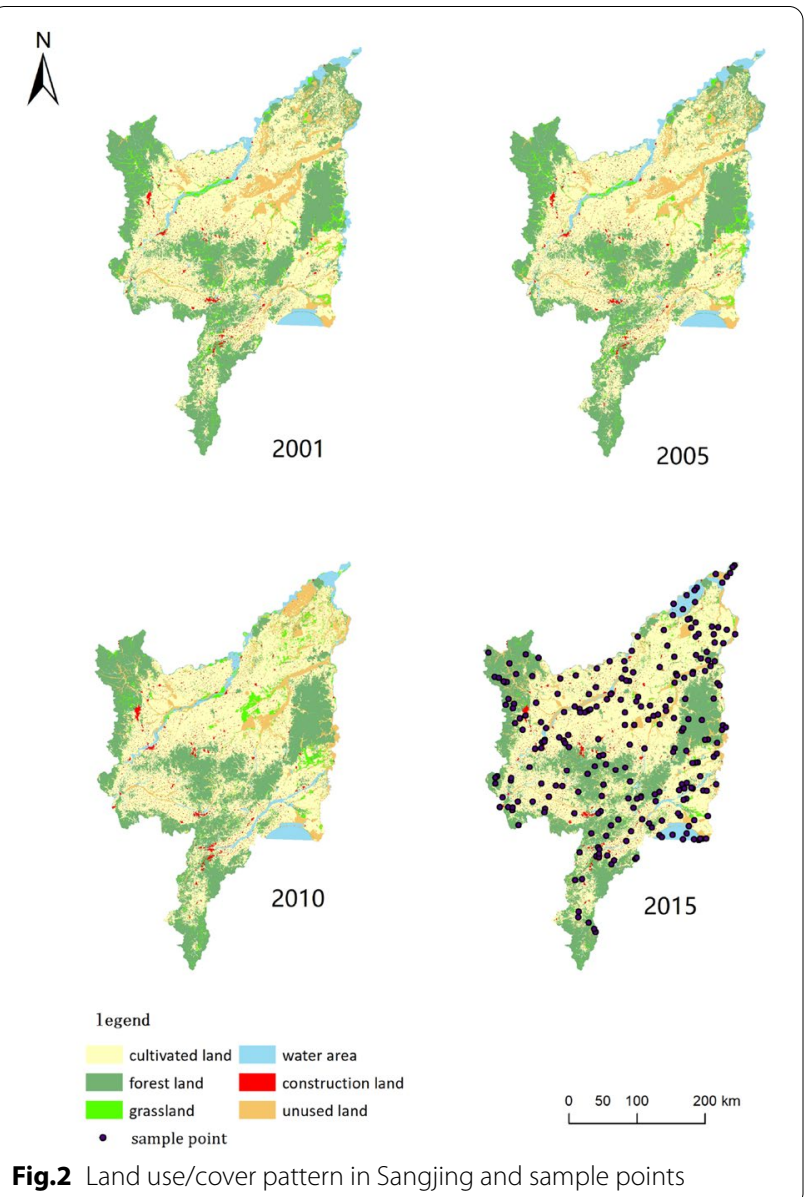


accuracy are over $90 \%$, and the kappa coefficient is above 0.85 , thus indicating that the accuracy of the classification results meets the research requirements.

\section{Dynamic change characteristics in land use/cover types}

Used the analysis function module of QGIS for statistical and spatial overlay analyses through the interpreted land use/cover status maps of the Sanjiang Plain in 2001, 2005, 2010 , and 2015. The land use/cover transition matrix of the Sanjiang Plain in 2001-2015 was obtained.

\section{Vegetation aboveground biomass model}

The modeling method was the main method used for estimating biomass. The forest land (Formula 1), cultivated land (Formula 2), grassland and unused land (Formula 3) vegetation biomass models used the research results of Zhao [16], Peng et al. [17], and Li [18], and the models were verified. 40 sample plots were made respectively in various land use/cover types of the study area, which were used to measure the dry weight of biomass and verify model reliability. For forest land, cultivated land, grassland, and unused land, the findings show that the accuracy of the biomass estimations and measurements reached above $85 \%$. Consequently, the research needs were met and model usage in the research area was warranted. The biomass density models were as follows:

$$
\begin{aligned}
& \mathrm{B} 1=5576.245 \times(\mathrm{NDVI})^{2}-6635.377 \times \mathrm{NDVI}+2002.202, \\
& \mathrm{~B} 2=87.0518+106.5892 \times \mathrm{NDVI}, \\
& \mathrm{B} 3=2113.575+2125.757 \times \mathrm{NDVI} .
\end{aligned}
$$

\section{Estimation of the vegetation carbon storage}

The carbon content of different vegetation biomass varies. This study adopted commonly used international conversion coefficient between biomass and $\mathrm{C}$ quantity (i.e., for forest land, the conversion rate is 0.5 ; for other land use/cover types, the rate is 0.45$)[19,20]$. In accordance with the vegetation biomass model of each land use/ cover type and its remotely sensed NDVI data,the raster calculator of QGIS was used to produce the vegetation biomass density data of different land use/cover types, multiplied by the corresponding conversion coefficients to obtain the carbon density data $\left(\mathrm{kg} \mathrm{C} / \mathrm{m}^{2}\right)$, and multiplied thereafter by their corresponding area data $\left(\mathrm{km}^{2}, 1\right.$ $\mathrm{km}^{2}=1 \times 10^{6} \mathrm{~m}$ ) to generate the vegetation carbon storage data $\left(\mathrm{Tg} \mathrm{C}, 1 \mathrm{Tg} \mathrm{C}=1 \times 10^{9} \mathrm{~kg} \mathrm{C}\right)$ of different land use/cover types.

\section{Related analysis}

This study used a pixel-based correlation analytical method [21, 22] to analyze the response of vegetation carbon storage in the Sanjiang Plain to climate change from 2001 to 2015. The temperature and precipitation data of 34 sites were interpolated with inverse distance weights to obtain meteorological raster data with the same projection and spatial resolution as the carbon storage data by using the QGIS software platform. The carbon storage of areas with unchanged land use type from 2001 to 2015 was extracted. On the based of the pixel correlation analysis method, the raster calculator in QGIS was used to calculate the pixel-by-pixel correlation coefficients between vegetation carbon storage and temperature and precipitation in the areas with unchanged land use types over the 15 years in the growing season of the Sanjiang Plain.

\section{Results and analysis}

\section{Dynamic changes in the vegetation carbon storage}

From 2001 to 2015, land use/cover types in the Sanjiang Plain were changed significantly and transformed frequently (Table 1). The area of cultivated land and construction land increased overall, and the area of forest land, grassland, water area, and unused land decreased overall. The areas of land use/cover types were ranked from top to bottom as follows: cultivated land, forest land, unused land, water area, construction land, grassland. Cultivated land is the land use type with the largest increase in area, with a total of $4407.5 \mathrm{~km}^{2}$ of forest land, $1218.1 \mathrm{~km}^{2}$ of grassland, $557.8 \mathrm{~km}^{2}$ of water area, 507.6 $\mathrm{km}^{2}$ of construction land, and $4393.7 \mathrm{~km}^{2}$ of unused land converted into cultivated land. Cultivated land is the major transferred-in land use/cover type of the above-mentioned types. The percentages of areas with unchanged land use/cover type over the 15 years in cultivated land, forest land, grassland, water area, construction land, and unused land are $90.86 \%, 81.15 \%, 8.16 \%$, $59.87 \%, 72.31 \%$, and $36.20 \%$, respectively. Spatially, such change and transformation means that forest land, cultivated land, and construction land were relatively stabilized, whereas grassland and unused land were minimally stabilized in the study area.

\section{Dynamic changes in the vegetation carbon densities and carbon storage}

In the study area, the inter-annual change of various vegetation carbon density data showed that the average vegetation carbon density took an uptrend in 20012015 , increasing from $1.27 \mathrm{~kg} \mathrm{C} / \mathrm{m}^{2}$ in 2001 to $2.12 \mathrm{~kg}$ $\mathrm{C} / \mathrm{m}^{2}$ in 2015 (Fig. 3). The vegetation carbon densities of cultivated land, grassland, and unused land had no 
Table 1 Statistics of area change for different land use/cover types from 2001 to $2015\left(\mathrm{~km}^{2}\right)$

\begin{tabular}{lcccccccc}
\hline Area & Cultivated land & Forest land & Grassland & Water area & Construction land & Unused land & $\begin{array}{c}\text { 2001 total area } \\
\text { Transferred- } \\
\text { out area }\end{array}$ \\
\hline Cultivated land & $\mathbf{4 7 , 6 2 2 . 8}$ & 1875.8 & 680.7 & 599.3 & 782.4 & 852.7 & $52,413.8$ & 4790.9 \\
Forest land & 4407.5 & $\mathbf{2 9 , 1 6 7 . 7}$ & 573.8 & 583.8 & 74.3 & 1134.7 & $35,941.8$ & 6774.1 \\
Grassland & 1218.1 & 1184.2 & $\mathbf{3 4 5 . 9}$ & 154.3 & 53.2 & 1267.9 & 4223.6 & 3877.7 \\
Water area & 557.8 & 78.9 & 72.3 & $\mathbf{3 1 1 5 . 6}$ & 18.9 & 1360.6 & 5204.0 & 2088.4 \\
Construction land & 507.6 & 36.6 & 12.6 & 7.5 & $\mathbf{1 5 2 8 . 0}$ & 20.8 & 2113.2 & 585.2 \\
Unused land & 4393.7 & 209.1 & 397.3 & 569.6 & 13.6 & $\mathbf{3 1 6 7 . 7}$ & 8751.0 & 5583.3 \\
2015 total area & $58,707.6$ & $32,552.3$ & 2082.6 & 5030.1 & 2470.4 & 7804.4 & $108,647.3$ & - \\
Transferred-in area & $11,084.8$ & 3384.6 & 1736.7 & 1914.5 & 942.4 & 4636.7 & - & - \\
Area change & 6293.9 & -3389.5 & -2141.0 & -173.9 & 357.2 & -946.6 & - & - \\
\hline
\end{tabular}

The transferred-out area of a land use/cover type is the difference between the total area of this land use/cover type in 2001 and the area of land that has not been converted. Meanwhile, the transferred-in area is the difference between the total area of this land use/cover type in 2005 and the area of land that has not been converted. The area change is the difference between the total area in 2015 and that in 2001 . The data in bold indicate the area of a certain land use/cover type that did not undergo conversion from 2001 to 2015

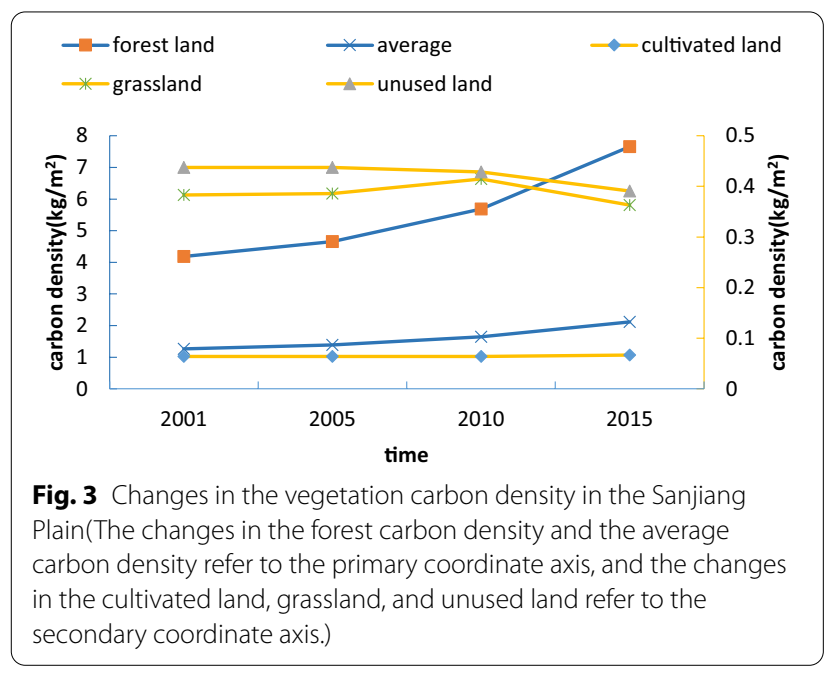

significant change, fluctuated between $0.06-0.07 \mathrm{~kg} \mathrm{C} /$ $\mathrm{m}^{2}, 0.36-0.41 \mathrm{~kg} \mathrm{C} / \mathrm{m}^{2}$ and $0.39-0.44 \mathrm{~kg} \mathrm{C} / \mathrm{m}^{2}$, respectively, but the vegetation carbon density of the forest land showed remarkable changes and increased continuously. The lowest and highest carbon densities of the forest land were 4.18 (2001) and 7.65 (2015) $\mathrm{kg} \mathrm{C} / \mathrm{m}^{2}$, respectively. For 15 years, the average carbon density of different vegetations were ranked from top to bottom as follows: forest land, unused land, grassland, and cultivated land.

In the study area, the inter-annual change of various vegetation carbon storage data showed that the vegetation carbon storage took an uptrend in 2001-2015, increasing from $159.18 \mathrm{Tg} \mathrm{C}$ in 2001 to $256.83 \mathrm{Tg} \mathrm{C}$ in 2015 (Fig. 4). The carbon storage of forest land vegetation significantly increased, from $150.38 \mathrm{Tg} \mathrm{C}$ in 2001 to $249.11 \mathrm{Tg} C$ in 2015 . The carbon storage of cultivated land vegetation also continued to increase, from 3.35 $\mathrm{Tg} \mathrm{C}$ in 2001 to $3.91 \mathrm{Tg} \mathrm{C}$ in 2015. The carbon storage

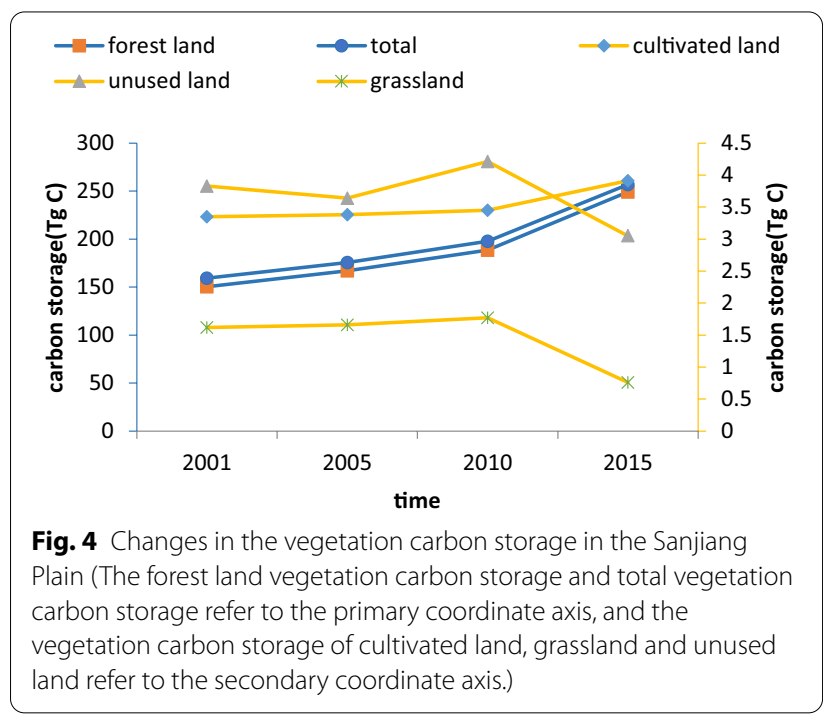

of grassland and unused land vegetation increased overall during 2010-2015 and decreased significantly during 2010-2015, mainly due to significant reductions in grassland and unused land area during this period. For 15 years, the carbon storage of different vegetations were ranked from top to bottom as follows: forest land, unused land, cultivated land, and grassland. The change in the vegetation carbon storage in the Sanjiang Plain was basically the same as that of the forest land carbon storage, indicating that the forest land carbon storage was the main factor that affected the change in the vegetation carbon storage in the area and the main contributor of carbon sink in the Sanjiang Plain.

In terms of spatial distribution (Fig. 5), the vegetation carbon density of forest land in the majority of the areas in the Sanjiang Plain increased faster with 

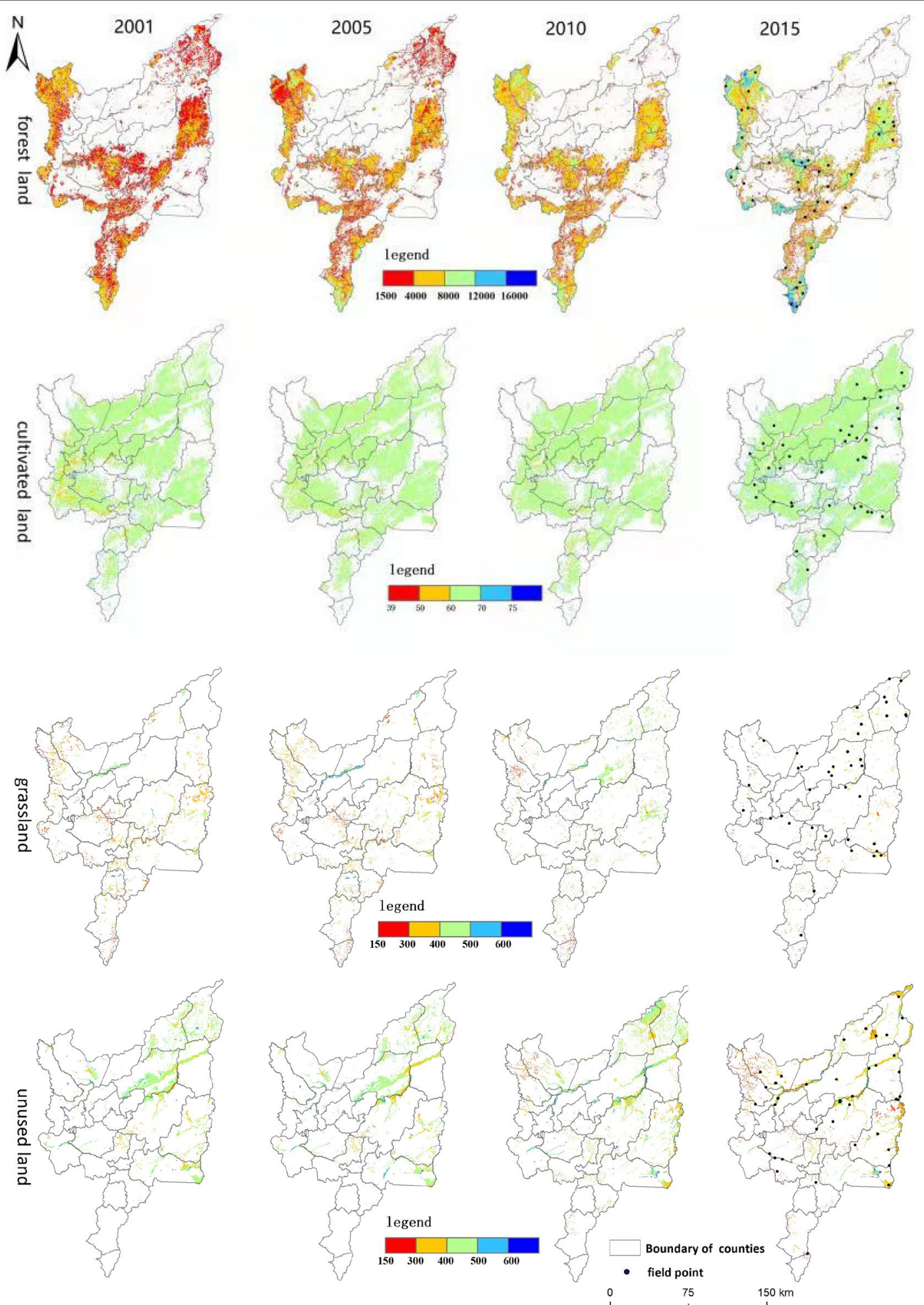

Fig. 5 Spatial distribution of carbon density of different vegetation in the Sanjiang Plain and field verification points of biomass models 
higher value; only the carbon density increase in the east was slower with a lower value. In 2001-2010, forest land with a vegetation carbon density of $1.5-8 \mathrm{~kg}$ $\mathrm{C} / \mathrm{m}^{2}$ accounted for over $80 \%$ of the total area but only $53.22 \%$ in 2015 . Areas with carbon density of above $8 \mathrm{~kg}$ $\mathrm{C} / \mathrm{m}^{2}$ generally exhibited an upward trend, which could mainly be attributed to forest growth, causing continuously high vegetation carbon density in some areas. In the different periods of 2001-2015, minimal differences were observed in the carbon density among cultivated land, grassland, and unused land, with a regional carbon density of $0.06-0.07 \mathrm{~kg} \mathrm{C} / \mathrm{m}^{2}$, accounting for $92 \%$ in cultivated land; and $0.3-0.5 \mathrm{~kg} \mathrm{C} / \mathrm{m}^{2}$, accounting for $82 \%$ in grassland and unused land. From 2001 to 2015, areas with remarkable carbon storage change were mainly distributed in northeast Sanjiang Plain, with extensive areas of forest land transformed into cultivated land, thereby significantly reducing carbon storage in the area.

\section{Response of vegetation carbon storage to land use/cover change}

Based on the above calculation method, the change in vegetation carbon storage and its net change value under each land use/cover change in different time periods from 2001 to 2015 were calculated (Table 2). The land use/cover changes in the three time periods from 2001 to 2015 resulted in the loss of vegetation carbon storage, of which the loss was the largest from 2005 to 2010, with a loss of $12.15 \mathrm{Tg}$ C, followed by a loss of $2.78 \mathrm{Tg} \mathrm{C}$ from 2005 to 2015. The land use/cover changes in the Sanjiang Plain from 2001 to 2015 resulted in a loss of $22.76 \mathrm{Tg} C$ of vegetation carbon storage. Given that the forest land has the highest carbon storage per unit area, the conversion of forest land to cultivated land, grassland, and unused land led to a reduction in carbon storage, with a total reduction $45.86 \mathrm{Tg} \mathrm{C}$ from 2001 to 2015. The conversion of cultivated land, grassland, and unused land to forest land led to an increase in carbon storage, with a total increase of $24.38 \mathrm{Tg} \mathrm{C}$. The conversion of cultivated land to forest land, grassland, and unused land from 2001 to 2015 led to an increase in carbon storage, with a total increase of $14.71 \mathrm{Tg} \mathrm{C}$. The conversion of forest land, grassland, and unused land to cultivated land led to a reduction in carbon storage, with a total reduction of $35.22 \mathrm{Tg}$ C.

Although the changes in various land use/cover types in the Sanjiang Plain from 2001 to 2015 led to a loss of vegetation carbon storage, the overall vegetation carbon storage of the Sanjiang Plain during the past 15 years has

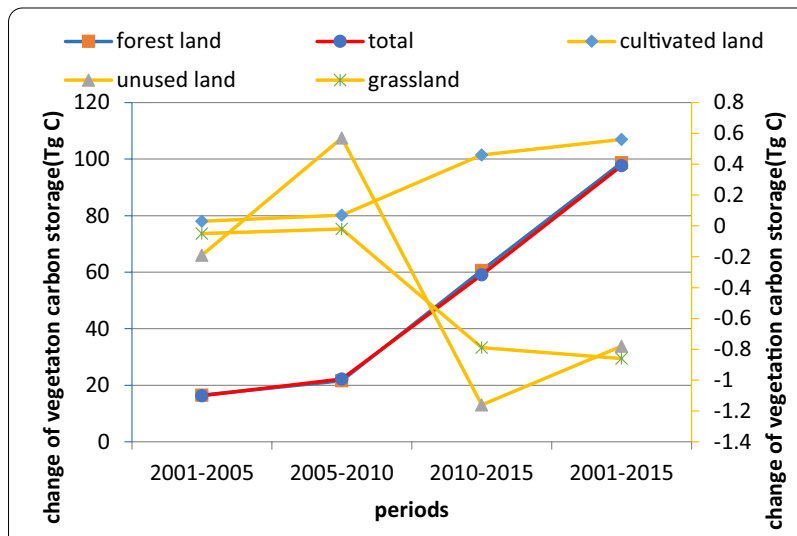

Fig. 6 Changes in the vegetation carbon storage at different time points in the Sanjiang Plain(The changes in the forest carbon storage and the total vegetation carbon storage refer to the primary coordinate axis, and the changes in the cultivated land, grassland, and unused land refer to the secondary coordinate axis)

Table 2 The change of vegetation carbon storage in the Sanjiang Plain during 2001-2015 (Tg C)

\begin{tabular}{|c|c|c|c|c|}
\hline Conversion of land use/cover types & 2001-2005 & $2005-2010$ & 2010-2015 & 2001-2015 \\
\hline Cultivated land $\rightarrow$ forest land & 0.26 & 10.52 & 0.82 & 14.23 \\
\hline Cultivated land $\rightarrow$ grassland & 0.03 & 0.45 & 0.09 & 0.20 \\
\hline Cultivated land $\rightarrow$ unused land & 0.01 & 0.69 & 0.05 & 0.28 \\
\hline Forest land $\rightarrow$ cultivated land & -0.57 & -19.69 & -2.29 & -33.44 \\
\hline Forest land $\rightarrow$ grassland & -0.17 & -4.01 & -0.19 & -4.18 \\
\hline Forest land $\rightarrow$ unused land & -0.03 & -8.07 & -0.02 & -8.24 \\
\hline Grassland $\rightarrow$ forest land & -0.02 & -0.32 & -0.71 & -0.36 \\
\hline Grassland $\rightarrow$ cultivated land & 0.05 & 6.84 & 0.17 & 8.63 \\
\hline Grassland $\rightarrow$ unused land & 0.00 & 0.01 & 0.01 & 0.04 \\
\hline Unused land $\rightarrow$ Cultivated land & -0.13 & -0.86 & -0.91 & -1.43 \\
\hline Unused land $\rightarrow$ forest land & 0.05 & 0.01 & 0.20 & 1.52 \\
\hline Unused land $\rightarrow$ grassland & 0.00 & -0.01 & 0.00 & -0.01 \\
\hline Net change of carbon storage & -0.53 & -14.46 & -2.78 & -22.76 \\
\hline
\end{tabular}


been increasing (Fig. 6), with an increase of $16.33 \mathrm{Tg} \mathrm{C}$ from 2001 to 2005, $22.23 \mathrm{Tg}$ C from 2005 to 2010, 59.09 $\mathrm{Tg} C$ from 2010 to 2015, and from 2001 to 2015 a total of $97.65 \mathrm{Tg} \mathrm{C}$. The vegetation carbon storage of cultivated land and forest land in the Sanjiang Plain from 2001 to 2015 has been increasing, while the vegetation carbon storage of grassland and unused land has been decreasing. The main reason for the increase in the vegetation carbon storage of cultivated land is the continuous increase of cultivated land area. The $6293.9 \mathrm{~km}^{2}$ increase of cultivated land area over the 15 years result in a 0.56 $\mathrm{Tg} C$ increase in vegetation carbon storage of cultivated land.

During this period, the area of the forest land decreased by $3389.5 \mathrm{~km}^{2}$, but the carbon storage of the forest land vegetation increased by $98.73 \mathrm{Tg} \mathrm{C}$, which was due to the increase in the carbon density of the forest land vegetation especially the continuously substantial increase in carbon density from 2005 to 2015. This increase compensated for the loss of the carbon storage caused by the reduction in the forest land area. The grassland area of the Sanjiang Plain was reduced by $2141.1 \mathrm{~km}^{2}$, thereby reducing the vegetation carbon storage of the grassland by $0.86 \mathrm{Tg} \mathrm{C}$. The area of unused land was also decreased by $946.6 \mathrm{~km}^{2}$, thereby reducing the vegetation carbon storage of unused land by $0.78 \mathrm{Tg} \mathrm{C}$. In summary, the conversion in different land use/cover types and the changes in vegetation carbon density led to changes in the vegetation carbon storage.

\section{Correlation analysis between the vegetation carbon storage and climate factors \\ Characteristics of temperature and precipitation change}

Temperature and precipitation data of the growing season in the Sanjiang Plain in 2001-2015 indicated that average monthly temperature and precipitation in 15 years consistenly increased, with change rates of $0.012{ }^{\circ} \mathrm{C} /$ year and $3.193 \mathrm{~mm} /$ year, respectively. Spatial distribution differences between temperature and precipitation in the Sanjiang Plain was evident, with the change intervals at $13.03-15.69^{\circ} \mathrm{C}$ and $57-86 \mathrm{~mm}$ and monthly temperature and precipitation of $14.89{ }^{\circ} \mathrm{C}$ and $66 \mathrm{~mm}$, respectively.

\section{Correlation analysis between the vegetation carbon density and climate factors}

In analyzing the response of vegetation carbon storage to climate change, in order to eliminate the changes in vegetation carbon storage caused by the mutual conversion of land use/cover types, a pixel-by-pixel correlation analysis was carried out on the vegetation carbon density and the average temperature and precipitation in the growing season in the areas with unchanged covertypes from 2001 to 2015 (Fig. 7). The results show that the vegetation carbon density in most of the forest land, cultivated land, grassland, and unused land was negatively associated with temperature, accounting for $66 \%, 71 \%$, $64 \%$, and $63 \%$, respectively, of the total area. Moreover, the vegetation carbon density in most of the areas was positively associated with precipitation, accounting for $77 \%, 63 \%, 72 \%$, and $55 \%$, respectively, of the total area (Tab. 3). Therefore, vegetation carbon density in most of the Sanjiang Plain was negatively and positively correlated with temperature and precipitation, respectively, during growing season. This result indicates that the increase of temperature mainly suppresses the vegetation carbon density, and the increase of precipitation mainly promotes it.

\section{Discussion}

Potential of vegetation carbon sink in the Sanjiang Plain

From 2000 to 2015, the average carbon density in the Sanjiang Plain was $1.61 \mathrm{~kg} \mathrm{C} / \mathrm{m}^{2}$, which was higher than that in the entire China (i.e., $1.47 \mathrm{~kg} \mathrm{C} / \mathrm{m}^{2}$ ) [23], while its average vegetation carbon storage was $197.32 \mathrm{Tg} \mathrm{C}$, accounting for $3.37 \%$ of the Chinese vegetation carbon storage [20], and the forest carbon storage in the Sanjiang Plain contributed $3.23 \%$. Compared with the China's overall vegetation productivity, the study area shows higher vegetation productivity, with its forest an important contributor to increased vegetation carbon storage and carbon sink. Forest carbon density was positively correlated with the age of stand (i.e., older trees contain higher carbon density) [24]. The young and half-mature forests account for nearly $70 \%$ of the forest area [25].

If the existing young and half-mature forests could grow to mature and post-mature forests, respectively, then forest biomass in the Sanjiang Plain has immense potential for carbon sink simply by growing within the same area. Therefore, the following measures should be taken to increase forest carbon sink: (1) Directly increase the forest area through afforestation. We will make full use of the land space such as sloping land, wasteland and abandoned mines to carry out afforestation projects, further expand the forest area and increase the total amount of forest resources. (2) Strengthen forest management and improve forest quality. We will strengthen the tending of young and half-mature forests and the restoration of degraded forests, increase the forest stock volume per unit area, and optimize the stock of forest resources.

\section{Impact of land use/cover changes in the Sanjiang Plain on vegetation carbon storage}

In 2001-2015, significant land use/cover change happened in the Sanjiang Plain, with cultivated land keeping up, while forest, grassland, and unused land 

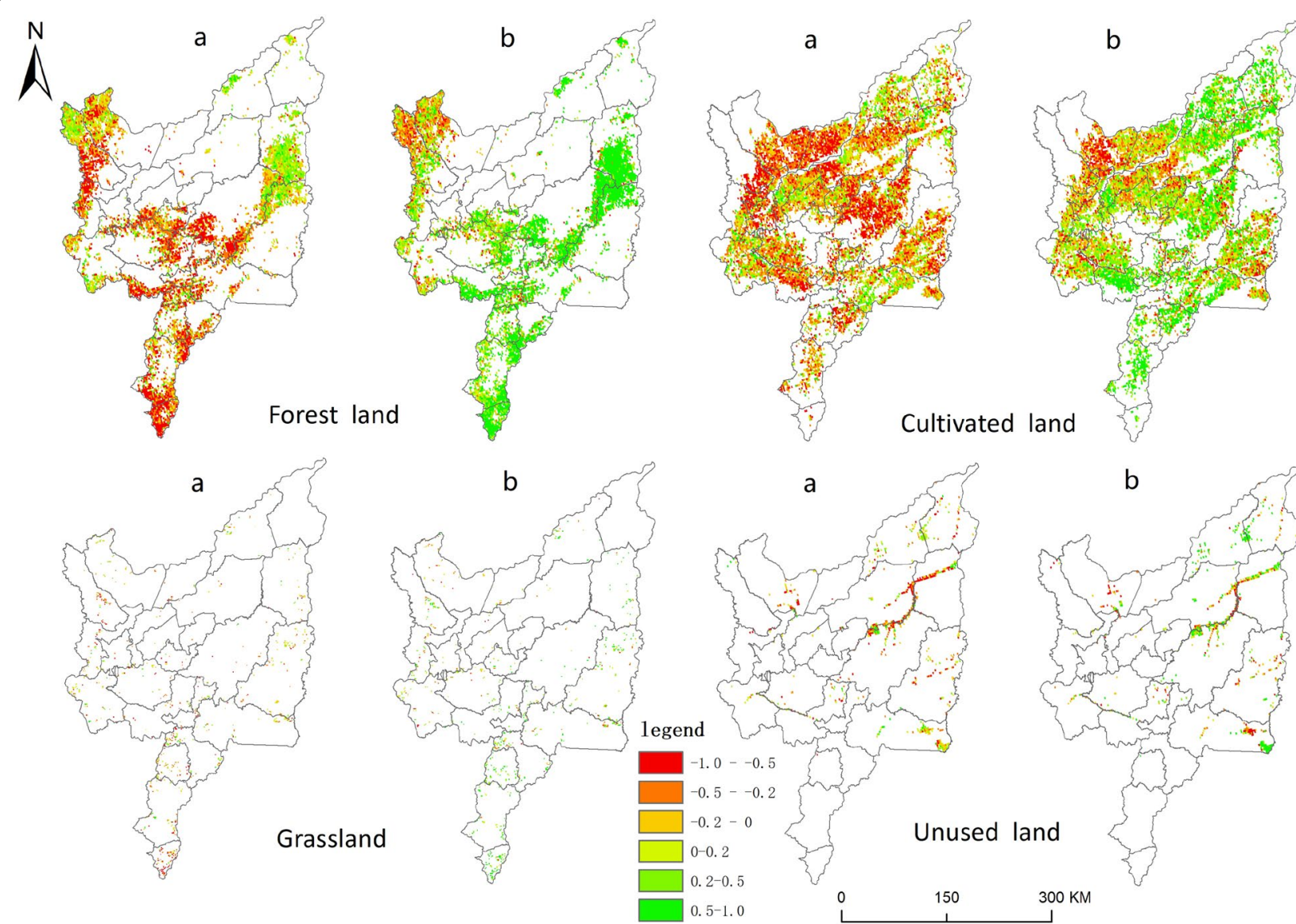

a

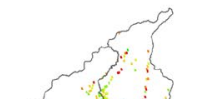

b

b

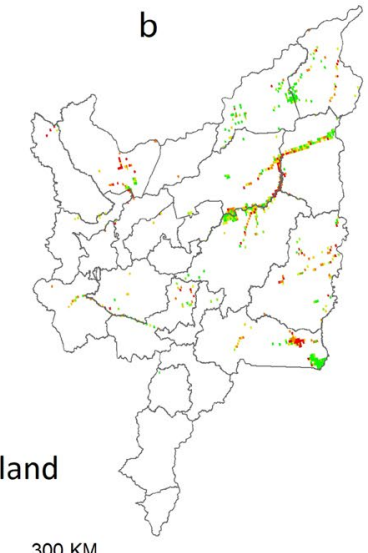

Fig. 7 Distribution of correlation coefficients of the vegetation carbon density with temperature (a) and precipitation (b) during the growing season in the region with unchanged vegetation type from 2001 to 2015

keeping down. Such a land use/cover change resulted in a decrease in vegetation carbon storage in the Sanjiang Plain. This result is consistent with that of Chang et al. [26], who only studied the change in vegetation carbon storage under different land use/cover change during various periods from 1954 to 2005 . Moreover, they did not assess vegetation carbon storage change from the carbon density perspective. The current study uses remote sensing data in four periods from 2001 to 2015 to consider change in vegetation carbon storage caused by back-and-forth conversion of land use/ cover types and also vegetation carbon density changes caused by actual vegetation growth. This process leads to a change in vegetation carbon storage in the research area. Between 2001 and 2015, land use/cover change in the Sanjiang Plain led to a loss of $22.76 \mathrm{Tg} C$ in vegetation carbon storage, but increased forest land carbon density added another $97.65 \mathrm{Tg} \mathrm{C}$ in such storage. Therefore, an increase in carbon density from forest land compensated for the loss of it owing to the change in land use/cover types.

\section{Impact of climate change on cegetation carbon storage in the Sanjiang Plain}

Increasing temperature has shown positive and negative effects on vegetation carbon storage. The positive effect shows that high temperature enhances photosynthesis efficiency and vegetation carbon storage increases. Meanwhile, the negative effect shows that substantial water consumption causes drought, thereby affecting vegetation carbon storage. From 2001 to 2015, the average temperature in the Sanjiang Plain increased, and vegetation carbon storage in the majority of the areas showed a negative correlation with temperature. This result indicates that a temperature increase in the region mainly inhibits vegetation carbon storage, which is consistent with the findings of Mao et al. [27]. The inhibitory effect of climate warming on vegetation carbon storage in the Sanjiang Plain may be caused by a reduction in soil water content and suppression of vegetation growth under high temperature conditions. Although climate warming partially promotes vegetation to capture additional $\mathrm{CO}_{2}$, the Sanjiang Plain is often windy with limited 


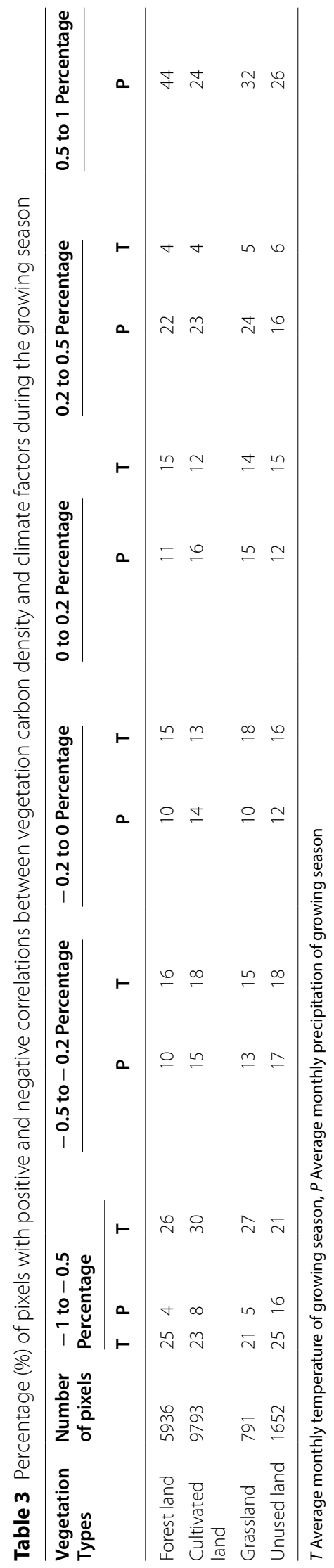


precipitation during the spring and hot in the summer. That is, surface evapotranspiration accelerated and lack of water was potentially exacerbated.

In 2001-2015, average precipitation during the growing season in the Sanjiang Plain continuously increased, and the majority of the regional vegetation carbon storage were positively correlated with precipitation. This condition indicates that an increase in precipitation in this area mainly promotes vegetation carbon storage. This outcome is consistent with the findings of $\mathrm{Xu}$ et al. [28]. Additional precipitation promoted vegetation carbon storage in the Sanjiang Plain is possibly related with the influence of water on vegetation, which is mainly done through water demand, water balance, and carbon sequestration within photosynthesis. Meanwhile, drought can cause a decrease in water, photosynthesis, transpiration and, in turn, accumulation of dry substances, thereby affecting the carbon storage of vegetation.

\section{Analysis of the ucertainty of vegetation carbon storage}

This study notes a relative uncertainty in estimating vegetation carbon storage. First, carbon content varies among different forest types, grassland types, and crop varieties. The average carbon content value of Chinese forest trees is over 0.45 ; broad-leaved trees, generally below 0.5 ; conifers, approximately at least 0.5 [29], grassland (unused land) plants, mainly between 0.35 and 0.47 [30]; and crops, mainly between 0.42 and 0.46 [31, 32]. Given the wide variety of plants in the study area, obtaining carbon contents of plants is relatively difficult. This study adopts the conversion coefficient of biomass and $\mathrm{C}$ quantity commonly used by the majority of scholars, specifically using 0.5 for forest land and 0.45 for other types, thereby causing some deviations in vegetation carbon storage. In addition, the spatial resolution of NDVI data is $250 \mathrm{~m}$, and the actual area of a single pixel in satellite image is $6.25 \times 10^{4} \mathrm{~m}^{2}$. Vegetation distribution in the study area is not uniform, resulting in some mixed pixel images, thereby affecting the inversion accuracy of vegetation carbon storage in the current study.

\section{Conclusion}

This study analyzes carbon density and carbon storage changes and their relationship with land use/cover change and climate from 2001 to 2015, specifically by using TM/OLI and MODIS NDVI remote sensing data and meteorological data. The main conclusion is that there is an upward trend for carbon storage and carbon density in the Sanjiang Plain. Carbon density growth is relatively fast in forest land insignificant in other land use/cover types. Land use/cover change reduces vegetation carbon storage, but high carbon density of forest vegetation compensates for such a loss. The results are as follows. Both changes of land use/cover types and vegetation carbon density directly lead to a change in vegetation carbon storage, and the continuous growth of forest land carbon density is the main factor for the overall increase of vegetation carbon storage. Temperature and precipitation during the growing season in the Sanjiang Plain increased in 15 years, vegetation carbon density in most of the Sanjiang Plain was negatively and positively correlated with temperature and precipitation, respectively. This result indicates that the increase of temperature mainly suppresses the vegetation carbon density, and the increase of precipitation mainly promotes it.

\section{Abbreviations \\ GIS: Geographic information system; NDVI: Normal difference vegetation index; MVC: Maximum value compositing; SVM: Support vector machine.}

\section{Acknowledgements}

Not applicable.

\section{Authors' contributions}

HYL carried out the overall study design and was a major contributor in writing the manuscript. CYL and YQ provided support and guidance for this study. XYZ and HQZ assisted data calculation and processing. LC carried out literature and examination. All authors read and approved the final manuscript.

\section{Funding}

The study is financially supported by the Basic Applicforeion Technology Research Project of Heilongjiang Provincial Institute of China (ZNBZ2020ZR06, ZNBZ2018ZR04) and National Natural Science Foundation of China (41971246).

Availability of data and materials

All data are available on request.

\section{Declarations}

Competing interests

The authors declare that they have no competing interests.

Received: 29 April 2021 Accepted: 29 September 2021

Published online: 20 October 2021

References

1. Lal R. Soil carbon sequestration to mitigate climate change. Geoderma. 2004;123:1-22. https://doi.org/10.1016/j.geoderma.2004.01.032.

2. Ni J. Index of vegetation-climate classification and its applications. Chin J Ecol. 1998;17(2):34-44 (in Chinese)

3. Li GD, Zhang JH, Chen C, et al. Research progress on carbon storage and flux in different terrestrial ecosystem in China under global climate change. Ecol Environ Sci. 2013;22(5):873-8. https://doi.org/10.3969/j.issn. 1674-5906.2013.05.025 (in Chinese).

4. Dai EF, Huang Y, Wu Z, et al. Spatial-temporal features of carbon sourcesink and its relationship with climate factors in Inner Mongolia grassland ecosystem. J Geog Sci. 2016;71(1):21-34. https://doi.org/10.11821/dlxb2 01601002 (in Chinese).

5. Fang JY, Yu GR, Ren XB, et al. Carbon sequestration in China's terrestrial ecosystems under climate change-progress on ecosystem carbon sequestration from the CAS strategic priority research program. Bull Chin Acad Sci. 2015;30(6):848-57. https://doi.org/10.16418/j.issn.1000-3045. 2015.06.019 (in Chinese) 
6. De Jong BHJ, Cairns MA, Haggerty PK, et al. Land-use change and carbon flux between 1970s and 1990s in central highlands of Chiapas. Mexico Environ Manag. 1999;23(3):373-85. https://doi.org/10.11821/dlxb201903 004.

7. Martens DA, Reedy TE, Lewis DT. Soil organic carbon content and composition of 130-year crop, pasture and forest land-use managements. Glob Change Biol. 2004;10(1):65-78. https://doi.org/10.1007/s002679900193.

8. Erb KH. Land use-related changes in aboveground carbon stocks of Austria's terrestrial ecosystems. Ecosystems. 2004;7(5):563-72. https://doi. org/10.1046/j.1529-8817.2003.00722.x.

9. Hutyra LR, Yoon B, Alberti M. Terrestrial carbon stocks across a gradient of urbanization: a study of the Seattle WA region. Glob Change Biol. 2011;17(2):783-97. https://doi.org/10.1007/s10021-004-0234-4.

10. Wu GW, Zhao YL, Fu YH, et al. Impact of reclamation-driven land use change on vegetation carbon store in mining areas. Chin J Eco-Agric. 2015;23(11):1437-44. https://doi.org/10.1111/j.1365-2486.2010.02238.x (in Chinese)

11. Kong JQ, Yang R, Su YZ, et al. Effect of land use and cover change on carbon stock dynamics in a typical desert oasis. Acta Ecol Sin. 2018;38(21):7801-12. https://doi.org/10.5846/stxb201711302156 (in Chinese).

12. Zhu WB, Zhang JJ, Cui YP, et al. Assessment of territorial ecosystem carbon storage based on land use change scenario: A case study in Qihe River Basin. Acta Geographica Sinica. 2019;74(3): 446-459. DOI: https:// doi.org/10.11821/dlxb201903004 (in Chinese)

13. Wei PP, Zan M. Changes of Land Coverage and the Impact on Vegetation Carbon Storage in Yili Region. J Northwest Forestry Univ. 2020;35(4):15866. https://doi.org/10.3969/j.issn.1001-7461.2020.04.25 (in Chinese).

14. Zhou T, Shi PJ. Impacts of Land Use Change on Soil Organic Carbon Change in China. Adv Earth Sci. 2006;21(2):138-43. https://doi.org/10. 3321/j.issn:1001-8166.2006.02.004 (in Chinese).

15. Liu JY. Study on National Resources \& Environment Survey and Dynamic Monitoring Using Remote Sensing. Journal of Remote Sensing. 1997;1(3):225-30 (in Chinese).

16. Zhao LQ. Remote sensing estimation of forest carbon stock in Beijing mountain[Paper]. Beijing: Forestry University; 2010. (in Chinese).

17. Peng $X$, Zhang SW. Research on rice growth status based on NDVI and LAI. Remote Sensing Technology and Application. 2002;17(1):12-6. https://doi.org/10.3969/j.issn.1002-1302.2005.06.004 (in Chinese)

18. Li S. The remote sensing estimation and analysis of aboveground biomass of vegetation in Honghe wetland nature reserve. Beijing: Capital Normal University; 2009. (in Chinese).

19. Caspersen JP, Paeala SW, Jenkins JC, et al. Contributions of land use history to carbon accumulation in US forests. Science. 2000;290(5494):114851. https://doi.org/10.1126/science.290.5494.1148.

20. Fang JY, Guo YD, Pu S, Chen AP. Estimation of terrestrial vegetation carbon sink in China from 198 to000, Science in China Series D. Earth Sci. 2007;37(6):804-12 (in Chinese).

21. Herrmann SM, Anyamba A, Tucker CJ. Recent trends in vegetation dynamics in the African Sahel and their relationship to climate. Glob
Environ Chang. 2005;15:394-404. https://doi.org/10.1016/j.gloenvcha 2005.08.004.

22. Lu Z, Lei GP, Guo YY, Ma QL. Changes of land use intensity in the Songnen Plain of different spatial scales and their effects on climatic factors. Acta Ecol Sin. 2021;41(5):1-13. https://doi.org/10.5946/stxb201911022309 (in Chinese)

23. Li KR, Wang SQ, Cao ML. Vegetation and soil carbon storage in China. Sci China, Ser D Earth Sci. 2003;33(1):72-80. https://doi.org/10.1360/02yd0 029 (in Chinese)

24. Zhang CH, Wang LY, Song QW, et al. Biomass carbon stocks and dynamics of forests in Heilongjiang Province from 1973 to 2013. China Environ Sci. 2018;38(12):4678-5468. https://doi.org/10.3969/j.issn.1000-6923.2018.12. 036 (in Chinese)

25. State Forestry Administration. China's forest resources report - the Eighth National Forest Resources Inventory. Beijing: China Forestry Press; 2014. ((in Chinese)).

26. Chang SZ, Wang ZM, Song KS, et al. Impact of land use and land cover change on the vegetation carbon storage in Sanjiang Plain. Ecological Science. 2010;29(3):207-14 ((in Chinese)).

27. Mao DH, Wang ZM, Song KS, et al. The vegetation NDVI variation and its responses to climate change and LUCC from 1982 to 2006 year in northeast permafrost region. China Environ Sci. 2011;31(2):283-92. https://doi. org/10.3969/j.issn.1008-8873.2010.03.003 (in Chinese)

28. Xu HM, Gao QZ, Huang YM, Jia HK. Simulated the impact of climate change on net primary production in hilly area of Loess Plateau China. Acta Ecol Sin. 2006;09:2939-47 (in Chinese)

29. Ma QY, Chen XL, Wang J, et al. Carbon content rate in constructive species of main forest types in northern China. J Beijing For University. 2002;24(5/6):96-100. https://doi.org/10.3321/j.issn:1000-1522.2002.05. 019 (in Chinese)

30. Ji B, HeE JL, Wang ZJ, et al. Characteristics and composition of vegetation carbon storage in natural grassland in Ning-xia. Chin J Appl Ecol. 2021;32(4):1259-68. https://doi.org/10.13287/j.1001-9332.202104.005 (in Chinese)

31. Zhang K, Luo HL, Wang R. Carbon Storage of Main Crops and Its Distribution during Last 5 Years (2008-2012) in Auyue County Sichuan Province. China J Agric Sci. 2017;30(8):1860-6. https://doi.org/10.16213/j.cnki.scjas. 2017.8.028 (in Chinese)

32. Zhu YW, Guan DS, Hu YP. Dynamic of vegetation carbon storage and carbon density of farmland ecosystem in Pearl River Delta. J Southern Agriculture. 2013;44(8):1313-7. https://doi.org/10.3969/j:issn.2095-1191. 2013.8.1313 (in Chinese)

\section{Publisher's Note}

Springer Nature remains neutral with regard to jurisdictional claims in published maps and institutional affiliations.

\section{Submit your manuscript to a SpringerOpen ${ }^{\circ}$ journal and benefit from:}

- Convenient online submission

- Rigorous peer review

- Open access: articles freely available online

- High visibility within the field

Retaining the copyright to your article

Submit your next manuscript at springeropen.com 